\title{
Linear and Non-linear Associations Between Platelet Count and Metabolic Parameters in Non- Diabetic and Non-Obese Elderly
}

\section{Szu-Han Chen}

Keelung Chang Gung Memorial Hospital of the CGMF https://orcid.org/0000-0001-8230-1197

Chieh-Hua Lu

Tri-Service General Hospital

\section{Yi-Lun Chiang}

Shin Kong Wu Ho Su Memorial Hospital

\section{Yen-Lin Chen}

Cardinal Tien Hospital

\section{Chang-Hsun Hsieh}

Tri-Service General Hospital

\section{Chung-Ze Wu}

Shuang Ho Hospital

Jiunn-Diann Lin

Shuang Ho Hospital

\section{Ying-Chung Chen}

Changhua Christian Medical Foundation Changhua Christian Hospital

\section{Te-Lin Hsia}

Cardinal Tien Hospital

Dee Pei ( $\square$ peidee@gmail.com )

Fu Jen Catholic University https://orcid.org/0000-0003-3080-4248

\section{Original investigation}

Keywords: platelet count, metabolic syndrome, metabolic parameters, non-linear association

Posted Date: July 20th, 2021

DOI: https://doi.org/10.21203/rs.3.rs-713971/v1

License: (1) (1) This work is licensed under a Creative Commons Attribution 4.0 International License.

Read Full License 


\section{Abstract}

Background: High platelet count was noted in people with metabolic syndrome. A significant association between platelet count and various metabolic parameters had also been reported. However, all the studies hypothesized that these associations are linear relationships. This work investigated the potential nonlinear relationships between platelet count and various metabolic parameters.

Methods: A cross-sectional analysis of data from 11198 non-diabetic, non-obese elderly in a Health Screening Center was undertaken to explore the relationship between platelet count and metabolic parameters, including metabolic syndrome, body mass index, waist circumference, body fat, systolic and diastolic blood pressure, fasting plasma glucose, cholesterol, triglyceride, high-density lipoprotein cholesterol, low-density lipoprotein cholesterol, C-reactive protein, insulin resistance, glucose effectiveness, and first-phase and second-phase insulin secretion. The linear relationship between platelet count and metabolic parameters was examined by linear and logistic regression. The non-linear relationship was investigated by the restricted cubic spline model.

Results: Multivariable regression analyses showed that a greater PC level was significantly associated with a greater risk of metabolic syndrome (odds ratio $1.025,95 \% \mathrm{Cl} 1.017$ to 1.032 ), a higher body fat, waist circumference, cholesterol, low-density lipoprotein, triglyceride, C-reactive protein, and insulin resistance, and lower high-density lipoprotein cholesterol and glucose effectiveness. The restricted cubic spline analysis adjusted for age and gender demonstrated a strong non-linearity on the relationship between platelet count and all the metabolic parameters, except systolic blood pressure, diastolic blood pressures, fasting plasma glucose, first-phase insulin secretion, and metabolic syndrome. The overall findings suggested a significant linear relationship between platelet count with the risk of metabolic syndrome, and a significant non-linear relationship between platelet count with many metabolic variables.

Conclusions: Platelet count is significantly associated with metabolic syndrome, metabolic parameters, and CRP in a linear or non-linear manner. The overall findings hint potential link between high platelet count, metabolic abnormalities, and chronic inflammatory status.

\section{Introduction}

Metabolic syndrome (MetS) is a common health problem worldwide, especially among elderly people (1, 2). It is characterized by the presence of abdominal obesity, impaired glucose tolerance, hypertriglyceridemia, decreased high density lipoprotein cholesterol (HDL), and hypertension. The presence of MetS is associated with a higher risk of cardiovascular diseases (3). Mottillo et al (4) in a meta-analysis showed that MetS is associated with a 2-fold increase in cardiovascular outcomes and a 1.5 -fold increase in all-cause mortality. Given that cardiovascular diseases are the leading causes of global death, an in-depth understanding of the pathophysiology for the link between MetS and cardiovascular disease is important. Ritchie et al (5) in a review conclude that MetS is associated with a 
pro-inflammatory state and this causes a significantly elevated cardiovascular risk. They advocate a better understanding of the molecular mechanism central to this association. Thus, an in-depth investigation of the underlying mechanism for high cardiovascular diseases in MetS is warranted.

Platelet abnormalities exist in patients with MetS (6). At the same time, platelet plays significant roles in the pathogenesis of cardiovascular diseases (7-10). Thus, the relationship between platelet abnormalities, MetS, and cardiovascular risks deserves our attention.

High platelet count (PC) had been observed in people with MetS (11-14). Zaccardi et al (15) in a metaanalysis confirmed that MetS was associated with a significantly higher PC. Chang et al (16) further demonstrated a significant association between PC and the individual component of MetS. As well, a significantly positive correlation between PC and insulin resistance (IR) was reported (17-19). However,

all previous studies on this topic hypothesize that the relationship between PC and metabolic profiles was linear. The possibility of a non-linear relationship has not been examined. Some contradictory findings were noted regarding the relationship between PC and MetS (20) and the relationship between PC and IR $(19,21)$. A non-linear relationship might explain the contradictory findings between studies with linear postulation. Several recent investigators had shown that the relationship between MetS and sleep duration (22), ferritin level (23), and dietary calcium intake (24) was non-linear. Also, a non-linear relationship between $\mathrm{BMI}$ and hypertension was reported (25).

In this work, we aim to examine the linear and non-linear relationship between PC and metabolic parameters in the non-diabetic, non-obese elderly. The research questions of this work are (1) Is there a significant association between PC and metabolic parameters? (2) Are the associations between PC and metabolic parameters non-linear?

\section{Methods}

This study is a cross-sectional design. Eligible participants were non-diabetic, non-obese (body mass index $(\mathrm{BMI})<27 \mathrm{~kg} / \mathrm{m}^{2}$ ) elderly $(>65 \mathrm{y} / \mathrm{o}$ ) who received a health check-up at MJ Health Screening Centers between 2011 and 2012. People who were taking medications that would affect the level of blood pressure, plasma glucose, and lipids levels were excluded from this study to avoid the impact of drugs on the levels of metabolic profiles. MJ Health Screening Centers are private chain clinics in Taiwan and the clinics provide regular health examinations to their members. Informed consent was obtained from all participants and the information of study participants was kept anonymous. The Institutional Review Board of MJ Health Screening Center had approved the study protocol.

On the day of the study, nursing staff recorded participants' medical history and information on current medications, and performed physical examinations. Waist circumference was measured horizontally at the level of the natural waist. BMI was calculated as the subject's body weight $(\mathrm{kg})$ divided by the square of the subject's height $(\mathrm{m})$. The cutoffs of BMI were defined according to the Department of Health in Taiwan: optimal BMI was defined as $18.5 \leqq \mathrm{BMI}<24 \mathrm{~kg} / \mathrm{m}^{2}$, overweight as $24 \leqq \mathrm{BMI}<27 \mathrm{~kg} / \mathrm{m}^{2}$, and 
obesity was defined as $\mathrm{BMI} \geqq 27 \mathrm{~kg} / \mathrm{m}^{2}$. Both systolic blood pressure (SBP) and diastolic blood pressure (DBP) were measured by standard mercury sphygmomanometers on the right arm of each participant in a seated position.

After fasting for 10 hours, blood samples were drawn for biochemical examination. Plasma was separated from the blood within 1 hour and stored at $-70^{\circ} \mathrm{C}$ until analysis. Fasting plasma glucose (FPG) was measured using a glucose oxidase method (YSI 203 glucose analyzer, Yellow Springs Instruments, Yellow Springs, USA). Total cholesterol and triglyceride (TG) was measured by using the dry, multilayer analytical slide method with the Fuji Dri-Chem 3000 analyzer (Fuji Photo Film, Tokyo, Japan). HDL and low-density lipoprotein cholesterol (LDL) concentrations were analyzed by using the enzymatic cholesterol assay following dextran sulfate precipitation. C-reactive protein (CRP) was measured by the latex agglutination method.

In this work, we used the equations developed by our research team to estimate IR (26), glucose effectiveness (GE) (27), first-phase insulin secretion (FPIS) (28), and second-phase insulin secretion (SPIS) (29). The equations for these metabolic parameters were listed in the following.

1. $I R=\log (1.439+0.018 \otimes$ gender $-0.003 \rrbracket$ age $+0.029 \otimes B M I-0.001 \otimes S B P+0.006 \otimes D B P+0.049 \otimes T G$ $-0.046 \otimes H D L-0.0116 \otimes F P G) \otimes 10^{3.333}$

(the correlation between the measured and calculated IR: $r=0.581, \mathrm{n}=307, p<0.001)(26)$.

2. $. \mathrm{GE}=(29.196-0.103 \otimes$ age $-2.722 \otimes \mathrm{TG}-0.592 \otimes \mathrm{FPG}) \otimes 10^{-3}$

(the correlation between the measured and calculated GE: $r=0.43, \mathrm{n}=227, p=0.001$ ) (27).

\section{FPIS $=10^{(1.477-0.119 \bowtie F P G+0.079 凶 B M I-0.523 凶 H D L)}$}

(the correlation between the measured and calculated FPIS: $r=0.671, \mathrm{n}=186, p<0.001)(28)$.

\section{4. $S P I S=10(-2.4-0.088 \otimes F P G+0.072 \otimes B M I)$}

(the correlation between the measured and calculated SPIS: $r=0.65, \mathrm{n}=82, p=0.002$ ) (29).

\section{Statistical analysis}

The demographic data and metabolic parameters in patients with and without MetS were compared using the chi-square test for categorical variables or independent sample t-test for continuous variables. Participants were further divided into four equal-sized subgroups according to the level of PC. The linear trend of the categorical variables across the ordinal subgroups by PC was tested using the CochranArmitage trend test. On the other hand, the linear trend of the continuous variables across quartiles of PC was tested using linear contrast in the general linear model. In addition to testing the linear trend, we also made pairwise comparisons among the quartiles of PC by using Bonferroni-correction post hoc of chi- 
square analysis for categorical variable and one-way analysis of variance for continuous variable respectively.

The linear relationship between PC (expressed as $\mu \mathrm{L} \times 10^{4}$ ) and metabolic parameters was assessed using univariate and multivariable regression analyses, where a logistic model was conducted for MetS and a linear model was performed for continuous metabolic parameters. Due to the individual components of FPIS, SPIS, IR and GE were overlapped with most of the metabolic parameters, therefore we only adjusted for age and sex in the multivariable model. Further, we evaluated the extent of non-linear association between PC and metabolic parameters by treating the continuous age as a flexible restricted cubic spline (RCS), in which the number of knots was 4, and locations were the 5th, 35th, 65th, and 95th percentiles(30), respectively. RCS modeling was performed with R, version 4.0.2 (R Foundation for Statistical Computing), and the package "rms" version 5.1-3.1 (Frank E. Harrell Jr). Other statistical analyses were undertaken by using SPSS 25 (IBM SPSS Inc, Chicago, Illinois).

\section{Results}

16542 elderly people were joining the health screening in MJ Health Screening Centers between 2011 and 2012. After excluding people not fulfilling the inclusion criteria, 11198 non-diabetic and non-obese participants, including 6170 men and 5028 women, were included. The mean age was $70.3 \pm 4.8$ years old. Their basic demographic data were shown in Table 1. A significant difference in PC, age, gender, all metabolic parameters (including BMI, waist circumference, body fat, blood pressure, FPG, cholesterol, triglyceride, HDL, LDL, IR, GE, FPIS, and SPIS) and CRP was noted between the MetS (+) and MetS (-) subgroups (Table 1). 
Table 1

Demographic data and metabolic parameters of the study participants

\begin{tabular}{|c|c|c|c|c|}
\hline Variable & All & MetS (+) & MetS (-) & $p$ value \\
\hline Number of participant & 11,198 & 3,050 & 8,148 & \\
\hline Platelet $\left(\mu \mathrm{L} \times 10^{3}\right)$ & $218.9 \pm 58.1$ & $226.2 \pm 59.4$ & $216.2 \pm 57.4$ & $<0.001$ \\
\hline Age (year) & $70.3 \pm 4.8$ & $70.7 \pm 5.0$ & $70.1 \pm 4.7$ & $<0.001$ \\
\hline Male & $6,170(55.1)$ & $1,345(44.1)$ & $4,825(59.2)$ & $<0.001$ \\
\hline Body mass index $\left(\mathrm{kg} / \mathrm{m}^{2}\right)$ & $22.7 \pm 2.5$ & $24.1 \pm 2.0$ & $22.2 \pm 2.5$ & $<0.001$ \\
\hline Waist circumference $(\mathrm{cm})$ & $79.8 \pm 8.0$ & $84.5 \pm 7.3$ & $78.1 \pm 7.6$ & $<0.001$ \\
\hline Body fat (\%) & $24.0 \pm 7.4$ & $27.9 \pm 6.8$ & $22.5 \pm 7.1$ & $<0.001$ \\
\hline Systolic blood pressure (mmHg) & $134.7 \pm 20.2$ & $143.4 \pm 18.6$ & $131.5 \pm 19.8$ & $<0.001$ \\
\hline Diastolic blood pressure $(\mathrm{mmHg})$ & $75.4 \pm 11.5$ & $79.2 \pm 11.2$ & $73.9 \pm 11.3$ & $<0.001$ \\
\hline Fasting plasma glucose (mg/dL) & $103.5 \pm 23.5$ & $112.9 \pm 32.7$ & $99.9 \pm 17.6$ & $<0.001$ \\
\hline Total cholesterol (mg/dL) & $206.2 \pm 38.0$ & $210.7 \pm 40.3$ & $204.5 \pm 36.9$ & $<0.001$ \\
\hline Triglyceride (mg/dL) & $120.8 \pm 62.4$ & $173.6 \pm 72.7$ & $101.1 \pm 44.0$ & $<0.001$ \\
\hline $\mathrm{HDL}(\mathrm{mg} / \mathrm{dL})$ & $54.9 \pm 15.6$ & $46.0 \pm 12.5$ & $58.3 \pm 15.4$ & $<0.001$ \\
\hline $\mathrm{LDL}(\mathrm{mg} / \mathrm{dL})$ & $127.1 \pm 33.4$ & $130.1 \pm 35.1$ & $126.0 \pm 32.7$ & $<0.001$ \\
\hline $\operatorname{IR}\left(10^{-4} \times \mathrm{min}^{-1} \times \mathrm{pmol}^{-1} \times \mathrm{L}^{-1}\right)$ & $3.67 \pm 0.02$ & $3.69 \pm 0.02$ & $3.66 \pm 0.02$ & $<0.001$ \\
\hline $\operatorname{GE}\left(10^{-2} \times \mathrm{dL} \times \min ^{-1} \times \mathrm{kg}^{-1}\right)$ & $0.015 \pm 0.002$ & $0.013 \pm 0.002$ & $0.016 \pm 0.002$ & $<0.001$ \\
\hline FPIS ( $\mu \mathrm{U} / \mathrm{min})$ & $90.6 \pm 62.2$ & $125.4 \pm 70.2$ & $77.6 \pm 53.4$ & $<0.001$ \\
\hline SPIS (pmol/mmol) & $0.059 \pm 0.024$ & $0.067 \pm 0.024$ & $0.056 \pm 0.023$ & $<0.001$ \\
\hline C-reactive protein (mg/L) & $0.35 \pm 1.05$ & $0.39 \pm 1.19$ & $0.33 \pm 1.00$ & 0.009 \\
\hline \multicolumn{5}{|c|}{$\begin{array}{l}\text { Abbreviations: MetS, metabolic syndrome; HDL, high-density lipoprotein; LDL, low-density lipoprotein; } \\
\text { IR, insulin resistance; GE, glucose effectiveness; FPIS, First phase insulin secretion, SPIS, Second } \\
\text { phase insulin secretion; }\end{array}$} \\
\hline
\end{tabular}

The linear trend analysis showed that the higher level of PC was correlated to younger age, a higher proportion of female, higher prevalence of MetS, lower waist circumstance but higher body fat (due to the distribution of sex), higher levels of cholesterol, triglyceride, LDL, IR and CRP and lower level of GE. However, no correlation between PC levels and BMI, blood pressure, FPG, HDL, FPIS, and SPIS was observed (Table 2). 
Table 2

Difference in demographic data and metabolic parameters in groups with different level of platelet counts

\begin{tabular}{|c|c|c|c|c|c|}
\hline \multirow[t]{2}{*}{ Variable } & \multicolumn{4}{|c|}{ Quartile by platelet count } & \multirow{2}{*}{$\begin{array}{l}\text { p for } \\
\text { linear } \\
\text { trend }\end{array}$} \\
\hline & Quartile 1 & Quartile 2 & Quartile 3 & Quartile 4 & \\
\hline Number of participant & 2,782 & 2,811 & 2,804 & 2,800 & \\
\hline Platelet count $\left(\mu \mathrm{L} \times 10^{3}\right)$ & $\begin{array}{l}153.5 \pm \\
24.2\end{array}$ & $197.5 \pm 9.4^{\mathrm{a}}$ & $\begin{array}{l}230.9 \pm \\
10.4^{\mathrm{ab}}\end{array}$ & $\begin{array}{l}293.4 \pm \\
48.2^{\mathrm{abc}}\end{array}$ & $<0.001$ \\
\hline Age (year) & $71.2 \pm 5.2$ & $70.2 \pm 4.7^{\mathrm{a}}$ & $69.9 \pm 4.5^{\mathrm{ab}}$ & $69.8 \pm 4.6^{\mathrm{ab}}$ & $<0.001$ \\
\hline Male & $\begin{array}{c}1,866 \\
(67.1)\end{array}$ & $\begin{array}{l}1,651 \\
(58.7)^{\mathrm{a}}\end{array}$ & $\begin{array}{l}1,406 \\
(50.1)^{\mathrm{ab}}\end{array}$ & $\begin{array}{l}1,246 \\
(44.5)^{\mathrm{abc}}\end{array}$ & $<0.001$ \\
\hline Prevalence of MetS & $633(22.8)$ & $724(25.8)$ & $786(28.0)^{a}$ & $906(32.4)^{a b c}$ & $<0.001$ \\
\hline $\begin{array}{l}\text { Body mass index } \\
\left(\mathrm{kg} / \mathrm{m}^{2}\right)\end{array}$ & $22.6 \pm 2.6$ & $22.8 \pm 2.5^{\mathrm{a}}$ & $22.7 \pm 2.5$ & $22.7 \pm 2.5$ & 0.209 \\
\hline Waist circumstance $(\mathrm{cm})$ & $80.3 \pm 8.3$ & $80.0 \pm 8.2$ & $79.5 \pm 8.0^{a}$ & $79.5 \pm 7.6^{a}$ & $<0.001$ \\
\hline Body fat (\%) & $22.1 \pm 6.9$ & $23.6 \pm 7.2^{\mathrm{a}}$ & $24.6 \pm 7.3^{\mathrm{ab}}$ & $25.6 \pm 7.6^{a b c}$ & $<0.001$ \\
\hline $\begin{array}{l}\text { Systolic blood pressure } \\
(\mathrm{mmHg})\end{array}$ & $\begin{array}{l}134.6 \pm \\
20.8\end{array}$ & $134.5 \pm 20.0$ & $134.8 \pm 19.7$ & $135.0 \pm 20.1$ & 0.388 \\
\hline $\begin{array}{l}\text { Diastolic blood pressure } \\
(\mathrm{mmHg})\end{array}$ & $75.4 \pm 11.9$ & $75.3 \pm 11.4$ & $75.4 \pm 11.4$ & $75.5 \pm 11.4$ & 0.703 \\
\hline $\begin{array}{l}\text { Fasting plasma glucose } \\
\text { (mg/dL) }\end{array}$ & $\begin{array}{l}103.2 \pm \\
22.7\end{array}$ & $103.5 \pm 23.4$ & $103.1 \pm 22.2$ & $104.0 \pm 25.4$ & 0.301 \\
\hline Cholesterol (mg/dL) & $\begin{array}{l}196.0 \pm \\
36.0\end{array}$ & $\begin{array}{l}206.3 \pm \\
37.8^{\mathrm{a}}\end{array}$ & $\begin{array}{l}209.8 \pm \\
36.1^{a b}\end{array}$ & $\begin{array}{l}212.7 \pm \\
39.8^{\mathrm{abc}}\end{array}$ & $<0.001$ \\
\hline Triglyceride (mg/dL) & $\begin{array}{l}107.9 \pm \\
55.9\end{array}$ & $\begin{array}{l}118.0 \pm \\
60.3^{\mathrm{a}}\end{array}$ & $\begin{array}{l}125.9 \pm \\
63.2^{\mathrm{ab}}\end{array}$ & $\begin{array}{l}131.3 \pm \\
67.0^{\mathrm{abc}}\end{array}$ & $<0.001$ \\
\hline $\mathrm{HDL}(\mathrm{mg} / \mathrm{dL})$ & $54.3 \pm 15.2$ & $55.1 \pm 15.8$ & $55.5 \pm 15.8^{\mathrm{a}}$ & $54.9 \pm 15.7$ & 0.070 \\
\hline
\end{tabular}

Abbreviations: MetS, metabolic syndrome; HDL, high density lipoprotein; LDL, low density lipoprotein; FPIS, first phase insulin secretion; SPIS, second phase insulin secretion; IR, insulin resistance; GE, glucose effectiveness;

Data are shown as frequency (percentage) or mean \pm standard deviation;

"a", "b", and "c" indicate significant difference $(p<0.05)$ versus quartile 1 , quartile 2 , and quartile 3 , respectively. 


\begin{tabular}{|c|c|c|c|c|c|}
\hline \multirow[t]{2}{*}{ Variable } & \multicolumn{4}{|c|}{ Quartile by platelet count } & \multirow{2}{*}{$\begin{array}{l}\text { p for } \\
\text { linear } \\
\text { trend }\end{array}$} \\
\hline & Quartile 1 & Quartile 2 & Quartile 3 & Quartile 4 & \\
\hline $\mathrm{LDL}(\mathrm{mg} / \mathrm{dL})$ & $\begin{array}{l}120.1 \pm \\
31.8\end{array}$ & $\begin{array}{l}127.7 \pm \\
33.3^{\mathrm{a}}\end{array}$ & $129.2 \pm 32.9^{\mathrm{a}}$ & $\begin{array}{l}131.5 \pm \\
34.6^{\mathrm{ab}}\end{array}$ & $<0.001$ \\
\hline FPIS ( $\mu \mathrm{U} / \mathrm{min})$ & $91.1 \pm 62.3$ & $91.3 \pm 61.9$ & $90.1 \pm 62.9$ & $90.0 \pm 61.8$ & 0.412 \\
\hline SPIS (pmol/mmol) & $\begin{array}{l}0.058 \pm \\
0.024\end{array}$ & $\begin{array}{l}0.060 \pm \\
0.024\end{array}$ & $0.059 \pm 0.024$ & $0.059 \pm 0.024$ & 0.343 \\
\hline $\begin{array}{l}\text { IR }\left(10^{-4} \times \mathrm{min}^{-1} \times \mathrm{pmol}^{-}\right. \\
\left.{ }^{1} \times \mathrm{L}^{-1}\right)\end{array}$ & $\begin{array}{l}3.665 \pm \\
0.024\end{array}$ & $\begin{array}{l}3.668 \pm \\
0.024^{\mathrm{a}}\end{array}$ & $\begin{array}{l}3.669 \pm \\
0.025^{\mathrm{a}}\end{array}$ & $\begin{array}{l}3.670 \pm \\
0.025^{\mathrm{ab}}\end{array}$ & $<0.001$ \\
\hline $\begin{array}{l}\mathrm{GE}\left(10^{-2} \times \mathrm{dL} \times \mathrm{min}^{-1} \times \mathrm{kg}^{-}\right. \\
1)\end{array}$ & $\begin{array}{l}0.0152 \pm \\
0.0020\end{array}$ & $\begin{array}{l}0.0149 \pm \\
0.0022^{\mathrm{a}}\end{array}$ & $\begin{array}{l}0.0147 \pm \\
0.0022^{\mathrm{ab}}\end{array}$ & $\begin{array}{l}0.0146 \pm \\
0.0022^{\mathrm{ab}}\end{array}$ & $<0.001$ \\
\hline C-reactive protein (mg/L) & $0.29 \pm 0.82$ & $0.30 \pm 0.98$ & $0.31 \pm 0.79$ & $\begin{array}{l}0.51 \pm \\
1.46^{\mathrm{abc}}\end{array}$ & $<0.001$ \\
\hline \multicolumn{6}{|c|}{$\begin{array}{l}\text { Abbreviations: MetS, metabolic syndrome; HDL, high density lipoprotein; LDL, low density lipoprotein; } \\
\text { FPIS, first phase insulin secretion; SPIS, second phase insulin secretion; IR, insulin resistance; GE, } \\
\text { glucose effectiveness; }\end{array}$} \\
\hline \multicolumn{6}{|c|}{ Data are shown as frequency (percentage) or mean \pm standard deviation; } \\
\hline
\end{tabular}

With adjustment of age and sex, the multivariable regression analyses showed that a greater PC level was significantly associated with a higher level of body fat, waist circumference, total cholesterol, LDL, triglyceride, CRP, and IR ( $P$ values $<0.05)$. In contrast, a higher PC level was significantly associated with a lower level of $\mathrm{HDL}$ (regression coefficient $-0.10,95 \%$ confidence interval [Cl] -0.15 to -0.05 ) and GE (regression coefficient $-0.40,95 \%$ confidence interval $[\mathrm{Cl}]-0.46$ to -0.33 ). In addition, the multivariable logistic model suggested that a greater PC level was significantly associated with a higher risk of MetS (odds ratio $1.025,95 \% \mathrm{Cl} 1.017$ to 1.032 ) (Table 3 ). 
Table 3

Univariate and multivariable regression analyses for the association between platelet count $\left(\mu \mathrm{L} \times 10^{4}\right)$ and metabolic parameters

\begin{tabular}{|c|c|c|c|c|}
\hline & Unadjusted & & Age and sex adjuste & \\
\hline Outcome & $\beta / O R$ 95\% (Cl) & $P$ & $\beta / O R$ 95\% (Cl) & $P$ \\
\hline Body fat (\%) & 0.20 (0.18 to 0.22$)$ & $<001$ & 0.06 (0.04 to 0.08$)$ & $\dot{0} 001$ \\
\hline Waist circumference $(\mathrm{cm})$ & $\begin{array}{l}-0.04(-0.07 \text { to } \\
-0.02)\end{array}$ & 0.001 & 0.03 (0.01 to 0.06$)$ & 0.009 \\
\hline Body mass index $\left(\mathrm{kg} / \mathrm{m}^{2}\right)$ & $\begin{array}{l}0.001(-0.007 \text { to } \\
0.009)\end{array}$ & 0.878 & $\begin{array}{l}-0.006(-0.014 \text { to } \\
0.003)\end{array}$ & 0.179 \\
\hline Systolic blood pressure $(\mathrm{mmHg})$ & $\begin{array}{l}0.008(-0.056 \text { to } \\
0.073)\end{array}$ & 0.800 & $\begin{array}{l}-0.002(-0.067 \text { to } \\
0.062)\end{array}$ & 0.940 \\
\hline $\begin{array}{l}\text { Diastolic blood pressure } \\
\text { (mmHg) }\end{array}$ & $\begin{array}{l}-0.002(-0.038 \text { to } \\
0.035)\end{array}$ & 0.933 & $\begin{array}{l}0.002(-0.035 \text { to } \\
0.039)\end{array}$ & 0.922 \\
\hline Cholesterol (mg/dL) & 0.91 (0.79 to 1.03$)$ & $<0.001$ & 0.70 (0.58 to 0.82$)$ & $\dot{0} 001$ \\
\hline $\mathrm{HDL}(\mathrm{mg} / \mathrm{dL})$ & $0.002(-0.05,0.05)$ & 0.937 & $-0.10(-0.15,-0.05)$ & $<_{0.001}^{<}$ \\
\hline $\mathrm{LDL}(\mathrm{mg} / \mathrm{dL})$ & 0.64 (0.53 to 0.74$)$ & $<0.001$ & $0.54(0.44$ to 0.65$)$ & $\dot{0} 001$ \\
\hline Triglyceride $(\mathrm{mg} / \mathrm{dL})$ & 1.39 (1.19 to 1.59$)$ & $<.001$ & 1.27 (1.07 to 1.47 ) & $\dot{0} 001$ \\
\hline C-reactive protein $(\mathrm{mg} / \mathrm{dL})$ & $\begin{array}{l}0.023(0.020 \text { to } \\
0.026)\end{array}$ & $<0.001$ & $\begin{array}{l}0.026(0.022 \text { to } \\
0.029)\end{array}$ & $\dot{0} 001$ \\
\hline $\begin{array}{l}\text { Fasting plasma glucose } \\
(\mathrm{mg} / \mathrm{dL})\end{array}$ & $0.05(-0.02$ to 0.12$)$ & 0.191 & $0.06(-0.02$ to 0.13$)$ & 0.132 \\
\hline FPIS $(\mu \mathrm{U} / \mathrm{min})$ & $-0.03(-0.22$ to 0.17$)$ & 0.796 & $0.15(-0.05$ to 0.35$)$ & 0.141 \\
\hline SPIS $\times\left(10^{4} \times \mathrm{pmol} / \mathrm{mmol}\right)$ & $0.01(-0.76$ to 0.78$)$ & 0.974 & $-0.60(-1.38$ to 0.17$)$ & 0.128 \\
\hline $\operatorname{IR}\left(10^{-1} \times \mathrm{min}^{-1} \times \mathrm{pmol}^{-1} \times \mathrm{L}^{-1}\right)$ & 0.24 (0.16 to 0.31$)$ & $<0.001$ & 0.12 (0.05 to 0.20$)$ & 0.002 \\
\hline $\mathrm{GE}\left(10^{2} \times \mathrm{dL} \times \min ^{-1} \times \mathrm{kg}^{-1}\right)$ & $\begin{array}{l}-0.35(-0.42 \text { to } \\
-0.28)\end{array}$ & $<001$ & $\begin{array}{l}-0.40(-0.46 \text { to } \\
-0.33)\end{array}$ & $<0.001$ \\
\hline $\begin{array}{l}\text { Metabolic syndrome (binary } \\
\text { outcome) }\end{array}$ & $\begin{array}{l}1.029 \text { (1.022 to } \\
1.037)\end{array}$ & $<0.001$ & $\begin{array}{l}1.025(1.017 \text { to } \\
1.032)\end{array}$ & $<_{0.001}^{<}$ \\
\hline
\end{tabular}


RCS analysis (4 knots) rejected the null hypothesis that there is a linear relationship between PC with all the examined variables ( $P$ for non-linearity $<0.05$ ), except FPG, systolic blood pressure, diastolic blood pressure, FPIS, and MetS. Thus, PC had significant associations with body fat, waist circumference, cholesterol, HDL, LDL, triglyceride, CRP, GE, and IR in both linear and non-linear models. However, our analysis showed that the non-linear model had a better fit than the linear model for body fat, cholesterol, LDL, triglyceride, CRP, GE, and IR based on a lower Akaike information criterion (AIC) and Bayesian information criterion (BIC). The results were inconsistent between AIC and BIC for waist circumference and HDL, suggesting that either linear or non-linear models are applicable for these two variables.

Alternatively, PC was significantly associated with BMI and SPIS in the non-linear model only. In contrast, there were neither linear nor non-linear associations between PC and FPG, systolic blood pressure, diastolic blood pressure, and FPIS.

Figure 1 depicts the graphic results of both the linear and RCS model for anthropometric measurements. The results demonstrated a non-linearity on body fat, waist circumference, and BMI. The PC levels were associated with greater body fat, waist circumference, and BMI values before approximately $250000 / \mu \mathrm{L}$ at a linear scale, while it turned to be a negative correlation afterward (inverted U shape, Fig. 1A-1C).

Figure 2 illustrates the graphic results of both linear and RCS models for laboratory data. The results demonstrated an apparent non-linearity on cholesterol, HDL, LDL, triglyceride, and CRP. Higher PC level was associated with greater levels of cholesterol, LDL, and triglyceride before approximately $250000 / \mu \mathrm{L}$ at a linear scale, whereas it reveals a slightly negative (inverted $U$ shape, Fig. 2A and $2 \mathrm{C}$ ) or null correlation afterward (upside down L shape, Fig. 2D). The PC level was slightly positively associated with $\mathrm{HDL}$ before $220000 / \mu \mathrm{L}$ and turned to be negatively associated with HDL afterward (Fig. 2B). The PC level was not associated with CRP level until approximately $250000 / \mu \mathrm{L}$ and it demonstrated that the association was linear afterwards (reverse $L$ shape, Fig. 2E).

Figure 3 displays the results of both linear and RCS models for glucose metabolism factors. These results showed that a higher PC level was associated with a greater SPIS level before approximately $200000 / \mu \mathrm{L}$, however, it reversed to be associated with a lower SPIS level after $200000 / \mu \mathrm{L}$ (inverted U shape, Fig. 3A). Higher PC level was associated with a lower GE value before approximately $250000 / \mu \mathrm{L}$, but the association tended to be null afterward (shallow U, Fig. 3B). Similar to the result of SPIS, a higher PC level was associated with a greater IR value before approximately $250000 / \mu \mathrm{L}$ and turned to be associated with a lower IR value afterward (inverted U shape, Fig. 3C). At last, the association between PC level and the risk of MetS seemed to be linear in nature (Fig. 4).

The graphic associations between PC and several non-significant variables, including systolic blood pressure, diastolic blood pressure, FPG, and FPIS, were shown in online supplementary Figures S1A-S1D.

\section{Discussion}


In this large health screening cohort, we found that PC positively predicts the risk of MetS in a linear manner. Also, we found a significant association between PC and many metabolic parameters, including body fat, waist circumference, BMI, cholesterol, triglyceride, HDL, LDL, SPIS, IR, and GE. Most of these associations are in a non-linear manner.

A significant relationship between MetS and high PC had been reported by previous authors (11-16). Fang et al (12) reported that PC had an odds ratio of 1.001 (95\% $\mathrm{Cl} 1.001-1.002)$ in predicting MetS in a health check-up population in Taiwan. Our findings in another health screening population in Taiwan showed that PC has an odds ratio of 1.025 (95\% $\mathrm{Cl} 1.017-1.032)$ in predicting MetS. The similar findings of both studies confirm the significant relationship between PC and MetS in the Taiwanese population. Our findings further suggested that this association is linear in nature.

Chang et al (16) reported significant associations between PC and FPG, cholesterol, triglyceride, and LDL. Our results also showed a significant linear and non-linear association between PC with cholesterol, triglyceride, and LDL. Visual inspection of spline curves and fitness examination by AIC and BIC suggested that the non-linear model had a better fit. In this work, we were unable to find a significant association between PC and FPG in neither linear nor non-linear models. This might be caused by the exclusion of the diabetic population in our participant enrollment.

Previous studies had shown a significant correlation between PC and body anthropometrics parameters, including body fat mass (31), waist circumstance $(31,32)$, and BMI $(31,33)$. However, some authors had revealed inconsistent findings. Alrubaie et al (34) found that there was an association between $\mathrm{BMI}$ and PC, but it was statistically insignificant. Raju et al (35) reported that PC was significantly associated with waist circumference, but not BMI. Our results demonstrated that $P C$ had a significant linear association with body fat and waist circumference, but not BMI. Alternatively, RCS analysis showed that PC had a significant non-linear association with all these three anthropometric parameters. Visual inspection of spline curves and fitness analysis by AIC and BIC again favored a non-linear association between PC and these anthropometric parameters.

The relationship between PC and glucose metabolism factors, including IR, GE, FPIS, and SPIS was also examined in this study. Of these, PC showed a significant non-linear association with IR, GE, and SPIS, but not FPIS. A positive relationship between PC and IR had been addressed by several investigators. Taniguchi et al (17) showed that IR was positively correlated with PC in univariate analysis and was independently predicted by PC in multivariate analysis in the Japanese population. Chen et al (18) showed that middle-aged and elderly Chinese with IR had a higher PC than those without IR. Park et al(19) found that when the highest PC quartile was compared with the lowest PC quartile, the odds ratio (adjusting for age, gender, and BMI) of being IR was 2.9 (1.39-6.07) in Korean adolescents. Our results also showed a significant association between PC and IR in the Taiwanese population. However, this relationship is actually non-linear. Spline curve showed that IR is associated with PC in an inverted U shape pattern, with a turning point at the PC of about $250000 / \mu \mathrm{L}$. The relationship between PC and other glucose metabolism factors, such as GE, FPIS, and SPIS, was rarely addressed in the literature. 
In addition to metabolic variables, we found that PC is also significantly associated with CRP in a reverse $L$ shape curve. A threshold effect was observed at PC of $250000 / \mu \mathrm{L}$. No association was found before this threshold. However, CRP increased linearly with PC after this point. The spline curve suggested that when the PC is greater than 250,000, the inflammation in the body will increase with PC.

The overall findings of this study suggest that significant associations between PC and metabolic parameters exist in a linear or non-linear manner. The underlying mechanism for such association is unclear. Jesri et al (11) found that MetS patients have higher PC and proposed that higher PC in MetS may serve as markers of a prothrombotic and proinflammatory state and contributors to atherothromboembolic risk. Our findings showed that high PC is simultaneously associated with high CRP and metabolic abnormalities. This finding supports a link between high PC, pro-inflammatory status and metabolic abnormalities.

There were several limitations in this study. First of all, the nature of cross-sectional design makes it difficult to establish the temporal relationships between PC and metabolic parameters. Future longitudinal studies may help establish the causal-relationship information between PC and metabolic parameters. Secondly, there is only one ethnic group in this study. It is difficult to generalize the findings of a study based on single ethnicity to the whole world population. Thirdly, we used indirectly calculated glucose metabolism factors (FPIS, SPIS, IR, and GE) rather than directly blood measured values in this study. The data obtained from indirect formula calculations might not be as accurate as those obtained from direct blood testing.

\section{Implication for Future studies}

The non-linear relationship between PC and metabolic parameters had rarely been investigated. Thus, more future studies are needed to confirm the findings of this research. Moreover, the underlying mechanism and clinical significance of these associations await future studies to delineate. In addition, the clinical meaning of the PC value of 200000 to $250000 / \mu \mathrm{L}$ as a turning point in most non-linear spline curves also deserves more studies to answer it.

\section{Conclusion}

The findings of this work suggested that PC is significantly associated with the risk of MetS and many metabolic parameters, including waist circumference, body fat, BMl, cholesterol, triglyceride, HDL, LDL, SPIS, IR, and GE, and inflammatory marker CRP, in a linear or non-linear pattern. These associations suggest the presence of a link between high PC, chronic inflammation, and metabolic abnormality. Such association might be a potential mechanism underlying the high prevalence of cardiovascular disease in patients with MetS.

\section{Abbreviations}


MetS: Metabolic syndrome; HDL: high density lipoprotein cholesterol; PC: platelet count; IR: insulin resistance; BMI: Body mass index; SBP: systolic blood pressure; DBP: diastolic blood pressure; DBP: diastolic blood pressure; FPG: Fasting plasma glucose; TG: triglyceride; LDL: low-density lipoprotein cholesterol; Cl: Confidence interval; CRP: C-reactive protein; GE: glucose effectiveness; FPIS: first-phase insulin secretion; SPIS: second-phase insulin secretion.

\section{Declarations}

\section{Ethics approval and consent to participate}

All subjects gave written informed consent. The study was approved by the Institutional Review Board of MJ Health Screening Center.

\section{Consent for publication}

Not applicable.

\section{Availability of data and materials}

The datasets used during the current study are available from the corresponding author on reasonable request

\section{Competing interests}

The authors declare that they have no competing interests.

\section{Funding}

This study was funded by the grand from Cardinal Tien Hospital No. CTH106A-2A15 and CTH106A-2A16.

\section{Authors' contributions}

Chieh-Hua Lu, Yen-Lin Chen, and Dee Pei conceived the study. Yen-Lin Chen and Szu-Han Chen performed the statistical analysis. Szu-Han Chen drafted the manuscript. All co-authors critically revised the manuscript. All authors read and approved the final manuscript.

\section{Acknowledgments}

None.

\section{References}

1. Arai H, Yamamoto A, Matsuzawa Y, Saito Y, Yamada N, Oikawa S, et al. Prevalence of the metabolic syndrome in elderly and middle-aged Japanese. Journal of Clinical Gerontology Geriatrics. 2010;1(2):42-7. 
2. Bechtold M, Palmer J, Valtos J, lasiello C, Sowers J. Metabolic syndrome in the elderly. Curr DiabRep. 2006;6(1):64-71.

3. Tune JD, Goodwill AG, Sassoon DJ, Mather KJ. Cardiovascular consequences of metabolic syndrome. Transl Res. 2017;183:57-70.

4. Mottillo S, Filion KB, Genest J, Joseph L, Pilote L, Poirier P, et al. The Metabolic Syndrome and Cardiovascular Risk: A Systematic Review and Meta-Analysis. J Am Coll Cardiol. 2010;56(14):111332.

5. Ritchie SA, Connell JM. The link between abdominal obesity, metabolic syndrome and cardiovascular disease. Nutrition, metabolism, and cardiovascular diseases. NMCD. 2007;17(4):319-26.

6. Santilli F, Vazzana N, Liani R, Guagnano MT, Davì G. Platelet activation in obesity and metabolic syndrome. Obes Rev. 2012;13(1):27-42.

7. Papapanagiotou A, Daskalakis G, Siasos G, Gargalionis A, Papavassiliou AG. The Role of Platelets in Cardiovascular Disease: Molecular Mechanisms. Curr Pharm Design. 2016;22(29):4493-505.

8. Peng F, Li Z, Yi C, Guo Q, Yang R, Long H, et al. Platelet index levels and cardiovascular mortality in incident peritoneal dialysis patients: a cohort study. Platelets. 2017;28(6):576-84.

9. Sloan A, Gona P, Johnson AD. Cardiovascular correlates of platelet count and volume in the Framingham Heart Study. Ann Epidemiol. 2015;25(7):492-8.

10. Molnar MZ, Streja E, Kovesdy CP, Budoff MJ, Nissenson AR, Krishnan M, et al. High platelet count as a link between renal cachexia and cardiovascular mortality in end-stage renal disease patients. Am J Clin Nutr. 2011;94(3):945-54.

11. Jesri A, Okonofua EC, Egan BM. Platelet and White Blood Cell Counts Are Elevated in Patients With the Metabolic Syndrome. The Journal of Clinical Hypertension. 2005;7(12):705-11.

12. Fang KC, Cheng YL, Su CW, Wang YJ, Lan KH, Huo TI, et al. Higher platelet counts are associated with metabolic syndrome independent of fatty liver diagnosis. Journal of the Chinese Medical Association: JCMA. 2017;80(3):125-32.

13. Lim HJ, Seo MS, Shim JY, Kim KE, Shin YH, Lee YJ. The association between platelet count and metabolic syndrome in children and adolescents. Platelets. 2015;26(8):758-63.

14. Kotani K, Sakane N, Saiga K, Mu H, Kurozawa Y. Clustered components of the metabolic syndrome and platelet counts in Japanese females. Clinical chemistry laboratory medicine. 2007;45(3):376-9.

15. Zaccardi F, Rocca B, Pitocco D, Tanese L, Rizzi A, Ghirlanda G. Platelet mean volume, distribution width, and count in type 2 diabetes, impaired fasting glucose, and metabolic syndrome: a metaanalysis. Diab/Metab Res Rev. 2015;31(4):402-10.

16. Chang YL, Pei C, Pei D, Tang SH, Hsu CH, Chen YL, et al. Association Between Platelet Count and Components of Metabolic Syndrome in Geriatric Taiwanese Males. International Journal of Gerontology. 2012;6(3):215-9.

17. Taniguchi A, Fukushima M, Seino Y, Sakai M, Yoshii S, Nagasaka S, et al. Platelet count is independently associated with insulin resistance in non-obese Japanese type 2 diabetic patients. 
Metab Clin Exp. 2003;52(10):1246-9.

18. Chen LK, Lin MH, Chen ZJ, Hwang SJ, Chiou ST. Association of insulin resistance and hematologic parameters: study of a middle-aged and elderly Chinese population in Taiwan. Journal of the Chinese Medical Association: JCMA. 2006;69(6):248-53.

19. Park JM, Lee JW, Shim JY, Lee YJ. Relationship Between Platelet Count and Insulin Resistance in Korean Adolescents: A Nationwide Population-Based Study. Metab Syndr Relat Disord. 2018;16(9):470-6.

20. Kotani K, Sakane N, Kurozawa Y. Relationship between age, metabolic syndrome and platelet counts in the male population. Ann Clin Biochem. 2007;44(Pt 5):495-6.

21. Yoshida K, Kimura T, Aoki T, Tsunekawa K, Araki O, Shoho Y, et al. Fasting serum insulin levels and insulin resistance are associated with blood rheology in Japanese young adults without diabetes. $J$ Int Med Res. 2016;44(3):496-507.

22. Fan L, Hao Z, Gao L, Qi M, Feng S, Zhou G. Non-linear relationship between sleep duration and metabolic syndrome: A population-based study. Medicine. 2020;99(2):e18753.

23. Ledesma M, Hurtado-Roca $Y$, Leon M, Giraldo P, Pocovi M, Civeira F, et al. Association of ferritin elevation and metabolic syndrome in males. Results from the Aragon Workers' Health Study (AWHS). J Clin Endocrinol Metab. 2015;100(5):2081-9.

24. Cheng L, Hu D, Jiang W. Dietary calcium intake and the risk of metabolic syndrome: evidence from observational studies. Public Health Nutr. 2019;22(11):2055-62.

25. Qu Y, Niu H, Li L, Li M, Yan S, Li M, et al. Analysis of Dose-response Relationship between BMI and Hypertension in Northeastern China Using Restricted Cubic Spline Functions. Sci Rep. 2019;9(1):18208.

26. Wu CZ, Lin JD, Hsia TL, Hsu CH, Hsieh CH, Chang JB, et al. Accurate method to estimate insulin resistance from multiple regression models using data of metabolic syndrome and oral glucose tolerance test. Journal of diabetes investigation. 2014;5(3):290-6.

27. Chen YL, Lee SF, Pei C, Pei D, Lee CH, He CT, et al. Predicting Glucose Effectiveness in Chinese Participants Using Routine Measurements. Metab Syndr Relat Disord. 2016;14(8):386-90.

28. Lin Jd, Hsu CH, Liang YJ, Lian WC, Hsieh CH, Wu CZ, et al. The Estimation of First-Phase Insulin Secretion by Using Components of the Metabolic Syndrome in a Chinese Population. International Journal of Endocrinology. 2015;2015:7.

29. Lin YT, Wu CZ, Lian WC, Hsu CH, Hsieh CH, Pei D, et al. Measuring second phase of insulin secretion by components of metabolic syndrome. International Journal of Diabetes Clinical Diagnosis. 2015;2:113-8.

30. Harrell F. Regression Modeling Strategies: With Applications to Linear Models, Logistic and Ordinal Regression, and Survival Analysis. Springer International Publishing; 2015.

31. Han S, Gan D, Wang G, Ru Y, Huang C, Lin J, et al. Associations of Platelet Indices with Body Fat Mass and Fat Distribution. Obesity (Silver Spring). 2018;26(10):1637-43. 
32. Jamshidi L, Seif A. Association Between Obesity, White Blood Cell and Platelet Count. Zahedan J Res Med Sci. 2017;19(2):e4955.

33. Samocha-Bonet D, Justo D, Rogowski O, Saar N, Abu-Abeid S, Shenkerman G, et al. Platelet counts and platelet activation markers in obese subjects. Mediators Inflamm. 2008;2008:834153-.

34. Alrubaire A, Majid S, Alrubaie R, Al-Zahraa B, Kadhim F. Effects of Body Mass Index (BMI) on complete blood count parameters. la Prensa Médica Argentina. 2019;105(5):164-71.

35. Raju S, Verma N, Tiwari S, Chandra T, Kumari R, Bhardwaj K. Study of Association between Platelet Function and Anthropometry of Blood Donors in a Single Institution. International Blood Research Reviews. 2016;6(4):1-8.

\section{Figures}
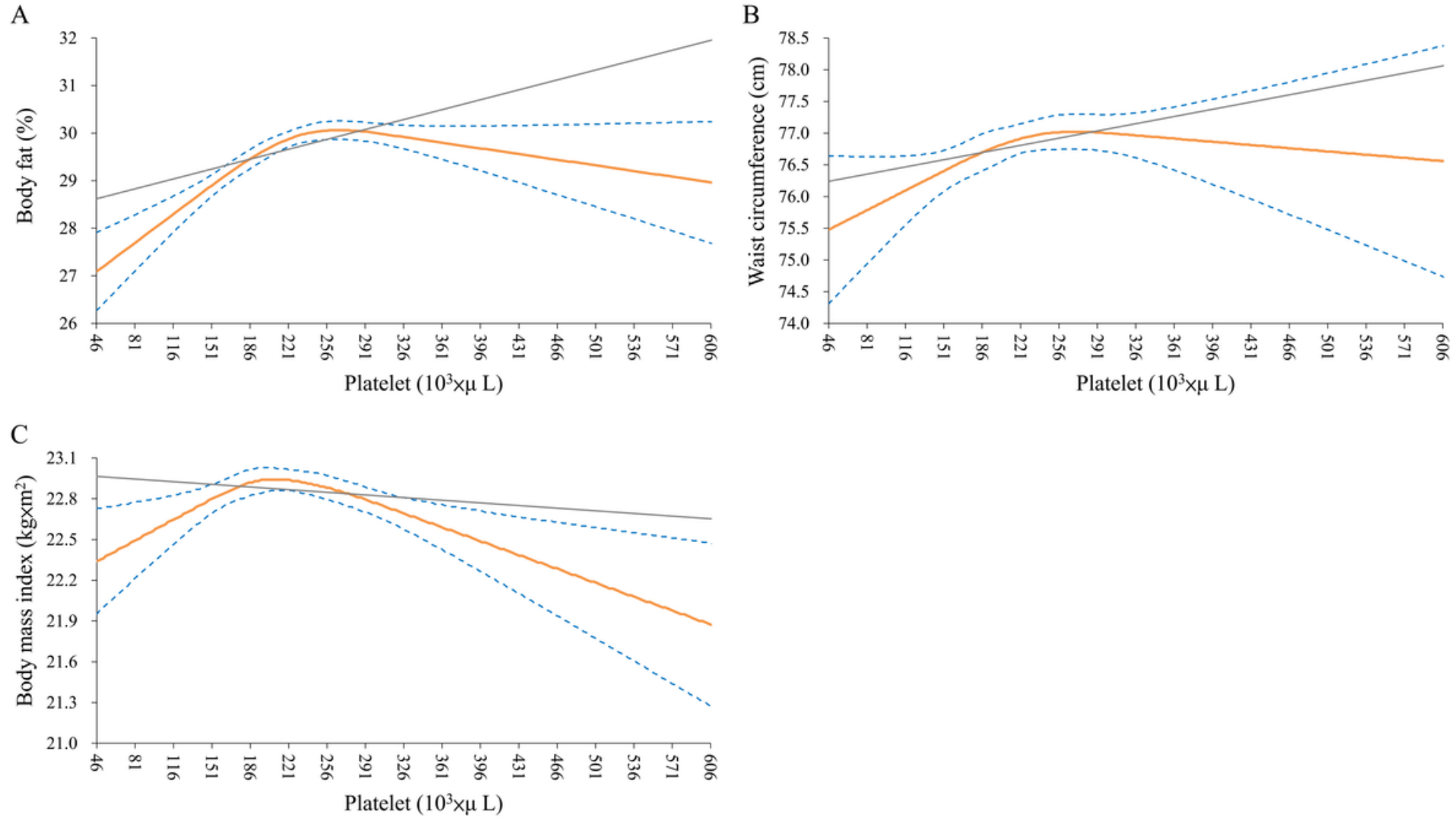

\section{Figure 1}

The linear and non-linear relationship between platelet count (treated as a restricted cubic spline) and anthropometric measurements, including body fat (A), waist circumference (B), and body mass index (C). 

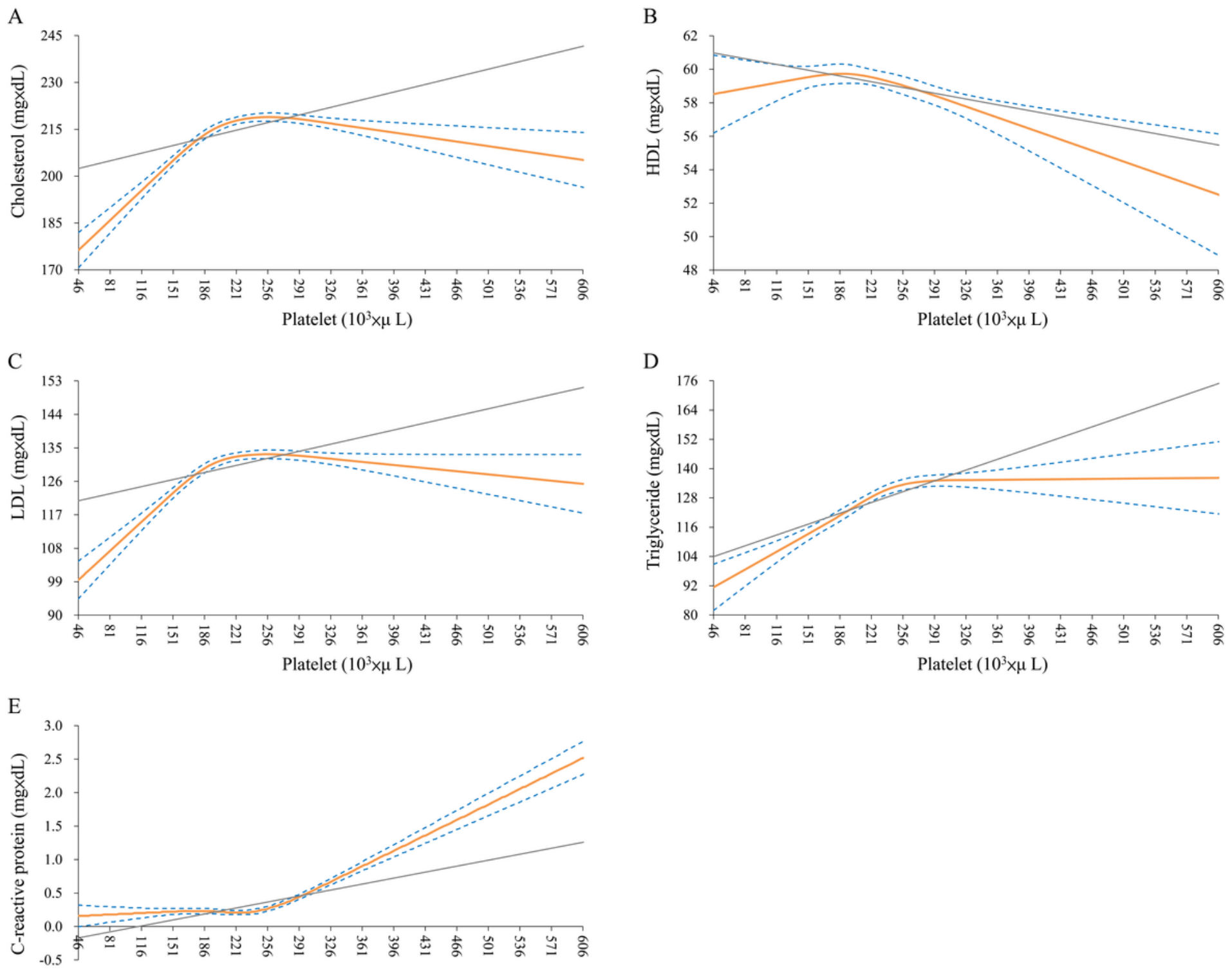

Platelet $\left(10^{3} \times \mu \mathrm{L}\right)$

\section{Figure 2}

The linear and non-linear relationship between platelet count (treated as a restricted cubic spline) and laboratory data, including cholesterol (A), HDL (B), LDL (C), triglyceride (D), and C-reactive protein (E). $H D L$, high density lipoprotein; LDL, low density lipoprotein. 
A
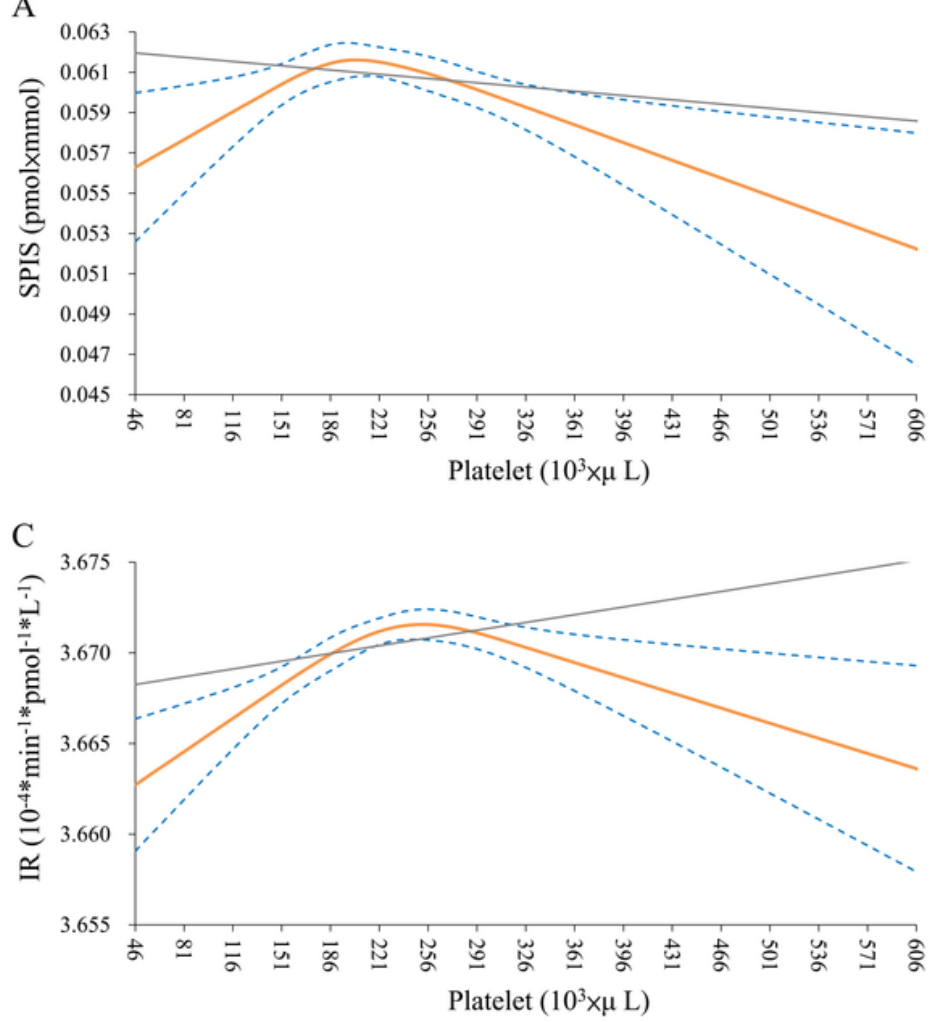

B

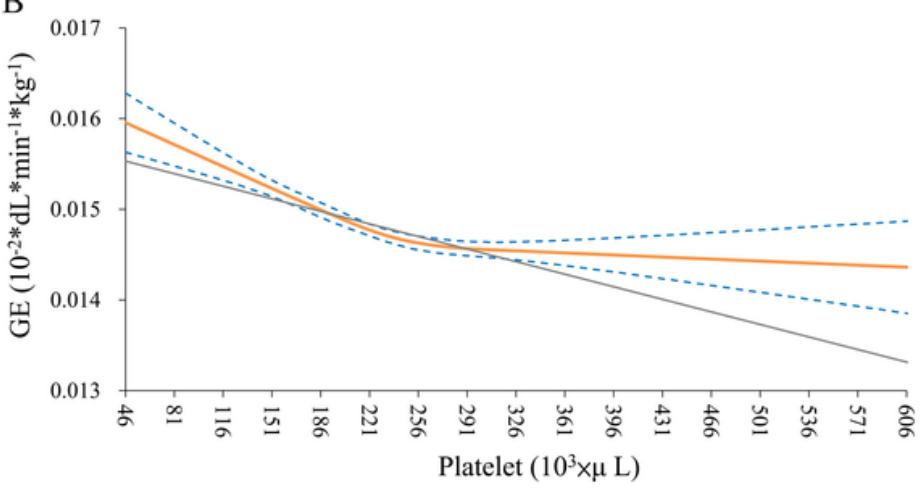

\section{Figure 3}

The linear and non-linear relationship between platelet count (treated as a restricted cubic spline) and glucose metabolism factors, including SPIS (A), GE (B), and IR (C). SPIS, second phase insulin secretion; $\mathrm{GE}$, glucose effectiveness; IR, insulin resistance.

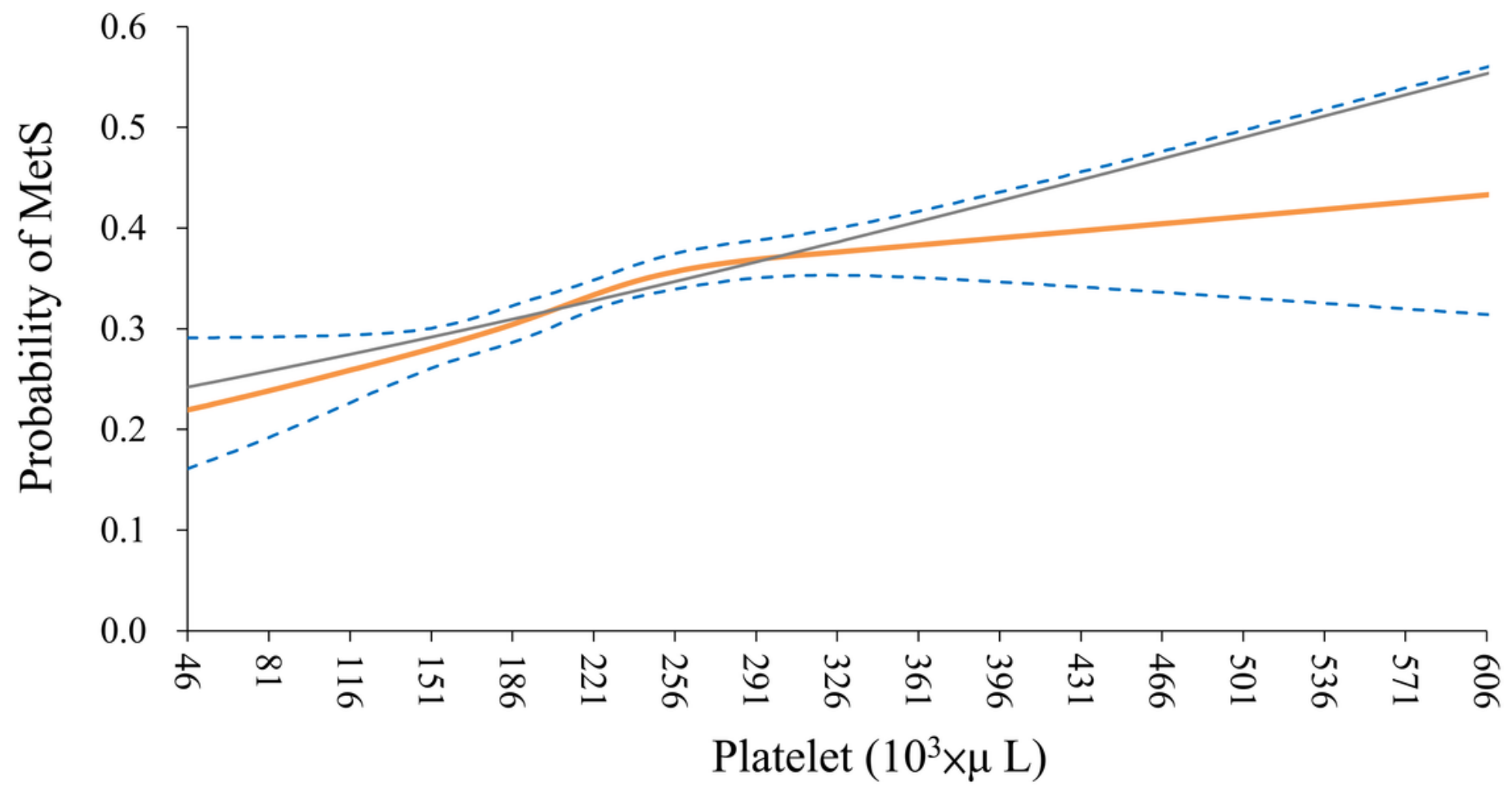


Figure 4

The linear and non-linear relationship between platelet count (treated as a restricted cubic spline) and the risk of metabolic syndrome. MetS, metabolic syndrome

\section{Supplementary Files}

This is a list of supplementary files associated with this preprint. Click to download.

- supplementarymaterial.docx 